\title{
Bioalgorithms for optical networks: New heuristic based on hyphae
}

\author{
Bioalgoritmos para redes ópticas: Nueva heurística basada en hifas
}

Arturo Rodriguez García ${ }^{1 *} \quad$ Renato Chavez Rosales ${ }^{2} \quad$ Ganga-Muñoz M. Angelica ${ }^{3}$

Recibido 9 de marzo de 2019, aceptado 12 de enero de 2020

Received: March 9, 2019 Accepted: January 12, 2020

\begin{abstract}
Optical networks have been positioned as high-speed networks whose switches must respond to requests at rates that did not occur before, determining that static traffic evolving into dynamic traffic caused the routing problem, and the wavelength assignment cannot be solved with optimization processes, giving rise to the appearance of heuristic algorithms which, because they are iterative processes, do not seek to optimize and find absolute optimums. It is only necessary to find a suitable solution, and in the case of networks this means a good route without it being the optimal route. Different strategies and algorithms have been used with outstanding results, and recently bioalgorithms have appeared that allow finding solutions from a biological perspective such as genetic and bacterial algorithms. In the present investigation, an algorithm based on fungal hyphae is proposed. The comparison of similar heuristics was performed through numerical simulation, where improvements were obtained with the proposed heuristic for the indicators under study. The results are encouraging and develop a performance that stands out among bioalgorithms.
\end{abstract}

Keywords: Bioalgorithms, heuristics, optical networks, light routing.

\section{RESUMEN}

Las redes ópticas se han posicionado como redes de alta velocidad donde sus conmutadores deben responder a solicitudes a tasas que antes no ocurrían, esto determinó que el tráfico estático evolucionar a tráfico dinámico generó que el problema de enrutamiento y asignación de longitud onda no pueda ser resuelto con procesos de optimización, dando lugar a la aparición de los algoritmos heurísticos que siendo procesos iterativos no buscan optimizar y encontrar óptimos absolutos. Solo es necesario encontrar una buena solución y para el caso de las redes esto significa una buena ruta sin que esta sea la ruta óptima. Se han utilizado diferentes estrategias y algoritmos con muy buenos resultados y últimamente aparecieron los bioalgoritmos que permiten encontrar soluciones desde una perspectiva biológica tales como los algoritmos genéticos, bacterianos y en la presente investigación se propone un algoritmo basado en hifas fúngicas. A través de la simulación numérica se realizó la comparación de heurísticas similares, donde se obtuvo mejoras con la heurística propuesta para los indicadores en estudio. Los resultados son alentadores y desarrollan un desempeño que se destaca entre los bioalgoritmos.

Palabras clave: Bioalgoritmos, heurísticas, redes ópticas, enrutamiento lumínico.

1 Universidad de Santiago de Chile (USACH). Facultad Tecnológica. Departamento de Tecnologías Industriales. Santiago, Chile. E-mail: arturo.rodriguez@usach.cl

2 Universidad de Santiago de Chile (USACH). Facultad de Química y Biología. Departamento de Biología. Santiago, Chile. E-mail: renato.chavez@usach.cl

3 Universidad de Santiago de Chile (USACH). Facultad Tecnológica. Departamento de Ciencia y Tecnología de los Alimentos. Santiago, Chile. E-mail: angelica.ganga@usach.cl

* Corresponding Author: arturo.rodriguez@usach.cl 


\section{INTRODUCTION}

In a world where the demand for data and information is constantly increasing, traffic in service and transport networks is getting increasingly complex. This technological development is meant to be oriented at increasing transport where light is a vehicle that allows the development of high speeds of Gbps and Tbps.

The new developments of optical technology aimed to improve the transport capacity through links, an increase of processing at the nodes (Optical Cross Connect - OXC) and the improvement of the routing algorithms and wavelength assignment. In the first case multifiber networks are being implemented, where each link has fibers and various wavelengths in each fiber, in this way multiplying the transport capacity of the link. In the second case, and as a consequence of the increased linkage capacity, OXCs have been developed with multiplexing capacities of fibers, wavelengths, wavelength bands, and time channels. Finally, in improving the routing and wavelength assignment algorithms, evolutionary algorithms are being conditioned to establish lightpaths (routes associated with wavelengths) which can decrease the probability of blocking and a low network use [15].

This technology is called Wavelength Division Multiplexing (WDM), where depending on the number of wavelengths used, they are classified into Coarse Wavelength Division Multiplexing(CWDM) with less than 10 wavelengths and Dense Wavelength Division Multiplexing(DWDM) with more than 10 wavelengths, allowing the exploitation at different levels and at different speeds. WDM provides support to the Synchronous Digital Hierarchy/ Synchronous Optical Network (SDH/SONET) which allow transporting the data in Synchronous Transport Module (STM) and Synchronous Transport Signal (STS) networks, establishing speeds from $155.52 \mathrm{Mbps}$ to $160 \mathrm{Gbps}$ approximately. In monofiber networks, the problem of finding a route and selecting a wavelength in the route is known a Routing Wavelength Assignment (RWA), and in the case of multifiber networks the fiber must be chosen in each link [1].

The route with its associated wavelength is called lightpath, and this problem is significantly more complex than routing in electronic networks. In monofiber networks the Wavelength Continuity Constraint (WCC) is implemented, which requires the same wavelength in the route and Wavelength Reuse (WR), which allows different wavelengths at each link, but this in turn requires e wavelength converters. In the case of multifiber networks the fiber continuity constraint (FCC) is added [3] The routing and wavelength assigning problem is approached from two solution perspectives, the first one finding the origin to destination route, and then associating the wavelength, and the second finding the route and the wavelength in the same algorithmic process. The heuristics have prevailed over the optimizing algorithms due to the ineffectiveness of the optimization for dynamic traffic where the solutions universe varies constantly depending on the demand for connection requests. The evolutionary algorithms are based on an initial population on which iterative procedures are performed that allow convergence towards a population that contains operational and functional routes, without needing to go over the total universe of solutions, allowing a high temporal efficiency to find several solutions in a single algorithmic process. These algorithms are obtained from natural processes like genetics, animal behavior such as snake, ant, bee, firefly, bat, etc., cooling of materials, among others $[5,10,12]$.

A new heuristic approach is developed basing the processes on biology, which are called bioalgorithms, where some are based on chromosomes and their combinatorial capacity as genetic algorithms, others on the behavior and structure of micoorganisms, like bacterial flagellum algorithms [11]. A novel case is the use of bacterial flagella in the search for optical network routes. The present research proposes the use of one of the most important structures of filamentous fungi, called hyphae, which are prolongations that allow the growth of these microorganisms, guaranteeing their survival. It should be mentioned that the fungi are the microorganisms which best adapt to the lack of resources scenarios, succeeding in surviving for long periods of time.

The main reproduction system of these microorganisms is sporulation, which allows the spores to disperse in a latent state, looking for a place with nutrients that allows their germination. At that time the spore divides, giving rise to the hyphae (filamentous structures) that grow in a direction that allows them 
the best development conditions, forming colonies that guarantee the survival of the species. The classification of hyphae is differentiated in three system, Monomitic, Dimitic and Trititic System. The first, is consist generative hyphaes, characterized for being always presents, and responsible for originating fertile structures. The second, consist generative hyphaes and skeletal or for generatives and enveloping. The third, consist in three hyphal types, generatives, skeletal and enveloping [7]. The hyphae can has septa or not, being one of its characteristics being able to regenerate broken septa. This regeneration can be by incorporation of a new wall of material (septum by division) or by growth of another wall (pseudosept). These conditions or this process are used in this study to find routes in which the nodes represent spores and are replicated in the populational matrix, orienting their direction to the lowest costs. Promising results are found, improving the probability of blocking with respect to previously tested heuristics.

\section{RWA}

In optical fiber networks, Optical Cross Connect (OXC) play an important role to achieve commutation of the fibers and wavelengths [11-12]. Figure 1 shows a WCC network of commuters which establishes the route from node 3 to node 6 . The route formed by the $e_{60}-e_{05}-e_{51}-e_{13}$ links has the wavelength $\lambda_{1}$ associated, constituting a lightpath with wavelength continuity restriction $\left(e_{60}-e_{05}-e_{51}-e_{13}, \lambda_{1}\right)$.

Figure 2 shows a WR commuter network in which the route from node 8 to node 5 is established, where the route formed by links $e_{81}-e_{13}-e_{34}-e_{45}$ has

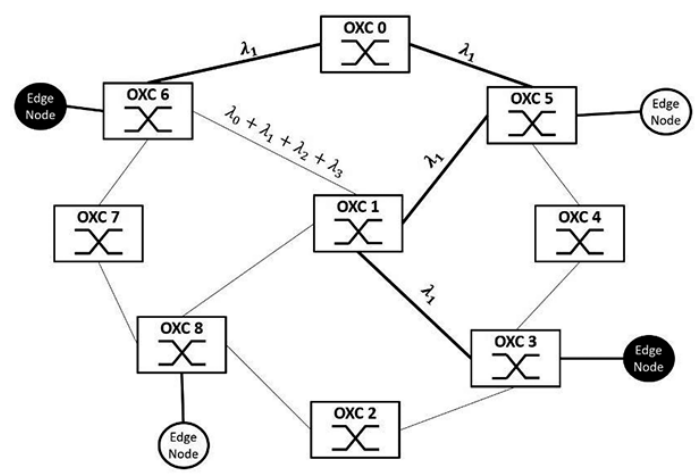

Figure 1. WDM-WCC network with four wavelengths.

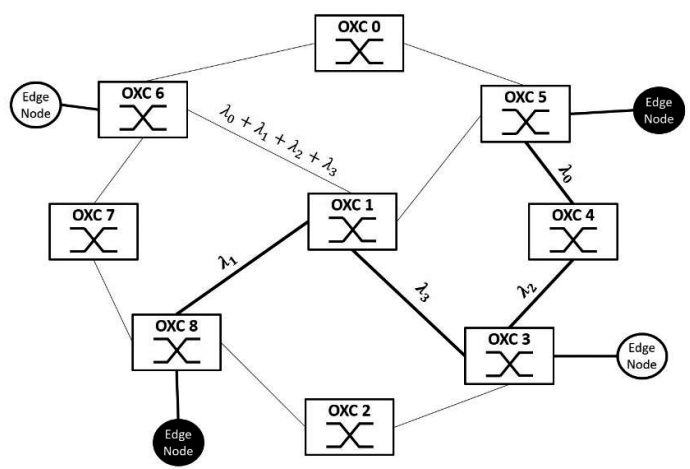

Figure 2. WDM-WR network with four wavelengths.

associated the wavelengths $\lambda_{1}, \lambda_{3}, \lambda_{2}, \lambda_{0}$, constituting a lightpath with reuse of the wavelength $\left(e_{81}\right.$, $\left.\lambda_{1}-e_{13}, \lambda_{3}-e_{34}, \lambda_{2}-e_{45}, \lambda_{0}\right)$.

The requests that get to the nodes are not storable, so if the request is not attended, it is blocked, and in this way the probability of blocking the requests has great importance in optical transport networks $[2,3]$. Since the traffic demands are dynamic, the universe of solutions is variable, so the conventional routing algorithms do not succeed in optimizing it, while the heuristics succeed in lightpaths which guarantee a low blocking probability.

\section{Heuristics and Metaheuristics}

If $\mathrm{n}$ is the number of nodes, $n_{W}$ is the number of wavelengths of a WCC optical network, $S_{i}$ is the request entering the $i$-th node, $n_{\text {Ciis }}$ the number of connections requested from the $i$-th node, $t_{C i}$ is the connection time requested from the $i$-th node, and $d i$ is the destination node time requested from the $i$-th node, so each request is established as shown in equation (1).

$$
S_{i}=\left(n_{c i}, t_{c i}, d_{c i}\right)
$$

Figure 3 shows the topology of an 8-node monofiber and 12 links, where each link has 16 connections available (costs) and eight wavelengths per link. Each node receives requests simultaneously and has the wavelength continuity restriction, which is that the same wavelength can be used only in each link that constitutes the route. This restriction limits the universe of solutions determining that the blocking probability increases, but its implementation is more economic than the networks with wavelength conversion. On the other hand, define the cost of a 


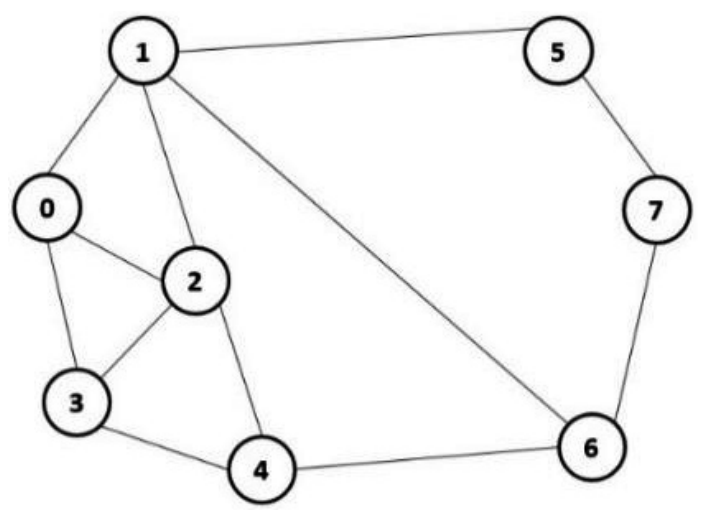

Figure 3. Topology of a WDM-WCC network with eight nodes $(N=8)$.

link is defined as $C_{i j}$, which measures the cost of the $i-j$ link.

Figure 4 shows the cost matrix associated with the network presented above, where the links that do not exist have a very high cost (999), so they are removed from the process every time the population matrix is arranged increasingly.

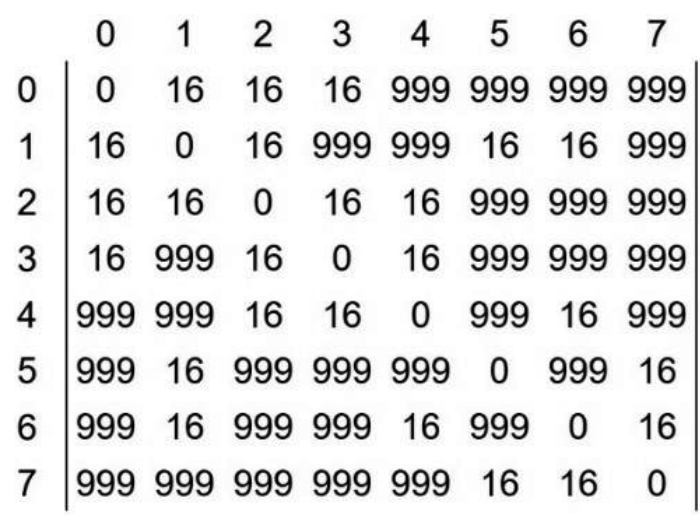

Figure 4. Cost matrix of an optical network.

The initial population is defined as $P 0$, composed of a matrix with $N$ rows, $N$ columns, and $M$ depth planes where $M$ represents the nodes that receive requests at the same time, so $M \leq N$, as shown in equation (2).
The algorithm has two stopping criteria, the first is for the maximum iterations limit that determines when the algorithmic process has been repeated and a solution has not been found, determining that the request is blocked. The second is for the rout's cost limit, where the solutions for establishing the lightpath are obtained.

Figure 5 shows the initial population for an 8-node network, where the ninth column is added for calculating the costs of the routes (rows), the nodes of origin and destination are placed in columns 0 and 7 , respectively, and columns from 1 through 6 are filled randomly. For example, the first route (row) has a cost of $C_{67}+C_{71}+C_{16}+C_{65}+C_{53}+C_{35}$ $+C_{53}$, which, looking in the costs matrix, gives: 16 $+999+16+16+16+16+16=1095$, which is saved in column 9 . Then the increasing arrangement is made, as shown in Figure 6.

The heuristic iterations are made in columns 1 through 6 , then the costs are recalculated, and the

\begin{tabular}{c|ccccccccc|} 
& 0 & 1 & 2 & 3 & 4 & 5 & 6 & 7 & Costos \\
0 & 6 & 7 & 1 & 6 & 5 & 3 & 5 & 3 & 1095 \\
1 & 6 & 4 & 1 & 0 & 4 & 7 & 2 & 3 & 3061 \\
2 & 6 & 7 & 6 & 3 & 0 & 2 & 3 & 3 & 2062 \\
3 & 6 & 0 & 4 & 1 & 1 & 7 & 3 & 3 & 4995 \\
4 & 6 & 0 & 5 & 1 & 2 & 3 & 4 & 3 & 5027 \\
5 & 6 & 1 & 1 & 5 & 2 & 2 & 6 & 3 & 4012 \\
6 & 6 & 7 & 1 & 6 & 6 & 6 & 2 & 3 & 2046 \\
7 & 6 & 2 & 5 & 1 & 4 & 6 & 0 & 3 & 6010
\end{tabular}

Figure 5. Initial population for an 8 -node $(N=8)$ network.

Figure 6. Initial population ordered increasingly.

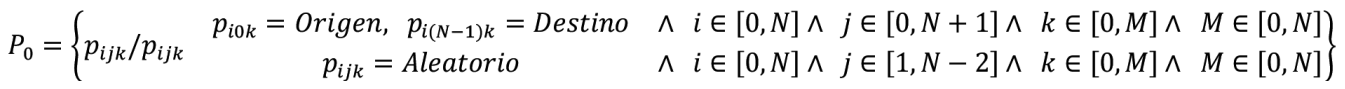


increasing arrangement is made again. Figure 7 shows the algorithmic process for any heuristic, and it is seen that it has two possible results: blocked request when the maximum limit of iterations determined in the algorithm itself, and lightpath the route that fulfills the aptitude function indicated in the stopping process.

The heuristic algorithms most widely studied in the literature are the genetic algorithms (GEN), simulated annealing (SAN), Taboo search (TSE), snake (SNK), and bacterial flagella (FBC) among others. However, some algorithms called Bioalgorithms are being developed and improving the results under traffic stress scenarios in optical transport networks, and the GEN and FBC algorithms belong to this group.

\section{Genetic Algorithm (GEN)}

Genetic algorithms have been studied since 1970. They were developed by John Henry Holland, and they have been applied in different settings where optimization is necessary without the need to find the absolute maximum. In optical transport they are used intensively due to their speed for finding routes. These algorithms use the chromosomic combination to generate populations with more and better characteristics according to an aptitude function. These processes yield better populations in which many routes appear in each iteration. This algorithmic process has subprocesses of chromosomic reproduction or combination, mutation, mortality, and in some cases natality [18].

For an explanation, a sample is extracted from Figure 6. Equation (3) shows four chromosomes of the initial population:

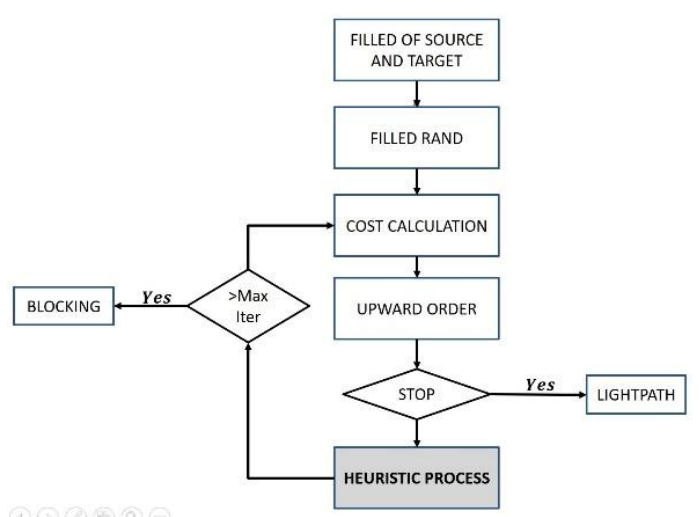

Figure 7. Flowsheet of an evolutionary algorithm.

$$
\left\{\begin{array}{llllllll}
6 & \mathbf{7} & \mathbf{1} & \mathbf{6} & \mathbf{5} & 3 & 5 & 3 \\
6 & 4 & 1 & 0 & \mathbf{4} & \mathbf{7} & \mathbf{2} & 3 \\
6 & \mathbf{7} & \mathbf{6} & \mathbf{3} & \mathbf{0} & 2 & 3 & 3 \\
6 & 0 & 4 & 1 & \mathbf{1} & \mathbf{7} & \mathbf{3} & 3
\end{array}\right\}
$$

Each chromosome is combined with the successive one, yielding new chromosomes with different characteristics and costs, see equation (4):

$$
\left[\begin{array}{llllllll}
6 & \mathbf{4} & \mathbf{7} & \mathbf{2} & 5 & 3 & 5 & 3 \\
6 & 4 & 1 & 0 & \mathbf{7} & \mathbf{1} & \mathbf{6} & 3 \\
6 & \mathbf{1} & \mathbf{7} & \mathbf{3} & 0 & 2 & 3 & 3 \\
6 & 0 & 4 & 1 & \mathbf{7} & \mathbf{6} & \mathbf{3} & 3
\end{array}\right]
$$

The new rows have different costs from those from the rows that generated them, developing a new population, setting up a process that improves the chromosomes until the aptitude function is fulfilled. The studies in Castrillón et al. [5] show the effectiveness of the process and its applicability in transport networks.

\section{Bacterial Flagella Algorithm (FBA)}

Bacteria are microorganisms (MOO) and their biological structure is unicellular, and in general they have a part that gives them motion which is called flagellum. This part allows them to move in search of zones with higher nutrient density. Depending on the number of flagella they are classified as Monotrichous when they have a single flagellum; Lophotrichous when they have multiple flagella at the same spot of the bacteria (pole); Amphitrichous when they have flagella on two poles of the bacteria, and Peritrichous when they have flagella on their whole perimeter [4]. Using equation (3) as an example, we see the establishment of the bacterial flagella in the population where each flagellum uses elements from two consecutive rows. The algorithm does not restrict the use of more than two rows, but for this example two are used.

$$
\left[\begin{array}{llllllll}
6 & 7 & 1 & 6 & 5 & 3 & 5 & 3 \\
6 & 4 & \mathbf{1} & 0 & \mathbf{4} & 7 & 2 & 3 \\
6 & \mathbf{7} & 6 & \mathbf{3} & 0 & \mathbf{2} & 3 & 3 \\
6 & 0 & \mathbf{4} & \mathbf{1} & \mathbf{1} & 7 & \mathbf{3} & 3
\end{array}\right]
$$

Equation (4) shows the rotation of the elements of the flagella, generating new rows that allow the overlap of the characteristics of both rows. This allows scanning the universe of solutions with the purpose of decreasing the cost of the routes, allowing to obtain solutions rapidly and effectively. 


$$
\left[\begin{array}{llllllll}
6 & 2 & 1 & \mathbf{1} & 5 & \mathbf{4} & 5 & 3 \\
6 & 4 & \mathbf{7} & 0 & \mathbf{6} & \mathbf{7} & \mathbf{3} & 3 \\
6 & \mathbf{3} & 6 & \mathbf{4} & 0 & \mathbf{1} & 3 & 3 \\
6 & 0 & \mathbf{7} & 1 & \mathbf{3} & \mathbf{7} & \mathbf{2} & 3
\end{array}\right]
$$

\section{Fungal Hyphae Algorithm (FHA)}

Among other structures, filamentous fungi have a network of cylindrical filaments called hyphae which allow their development and guarantee the permanence of the microorganism [8]. These hyphae are made of cell replicas that allow the continuity of the growth process if no nutrients are found in one direction (Figure 8) [14]. They are formed by a column of long tubular cells surrounded by a cell wall, and a group of hyphae constitutes a mycelium. The segmentations of the hyphae form the division of the filament into cells also called septa, and the separation between septa is given by partitions, which in addition to positioning the cell in the septum allow cytoplasmic separation, but on the other hand, not all the fungi present this morphology, and in this case they are called cenocytic [4].

These filaments grow in a given direction oriented by the existence of nutrients in the surroundings, in this way guaranteeing its feeding and development. In the case of the populational matrix, each node represents a spore, and that value is replicated following the highest cost direction or simply the existence of a given cost, since the aim is not to optimize, but

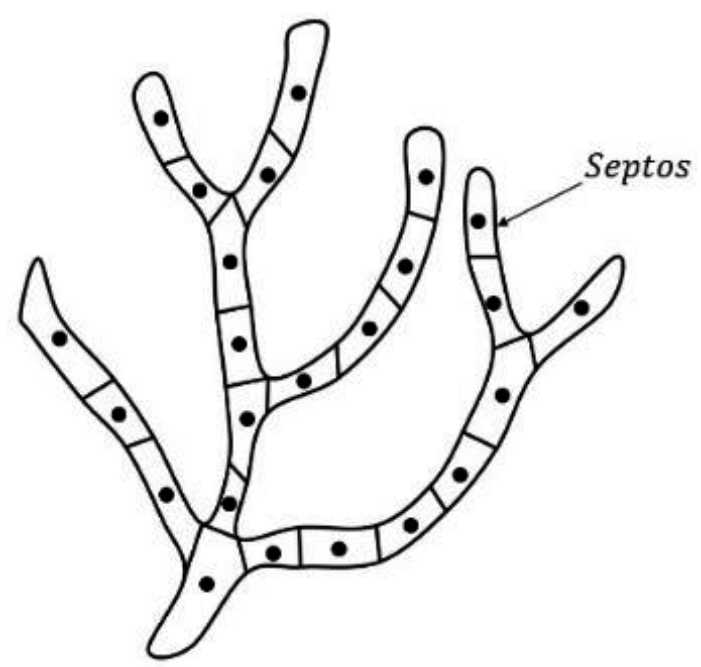

Figure 8. Diagram of a fungal hyphae showing its septa. only to find a route. In the case of the proposed algorithm the best cost was sought, However, the temporal complexity would decrease if only an existing cost smaller than the maximum number of channels and other than 0 is used. Figure 9 shows element $p_{i j}$ and its possible displacements, where the reply's anticlockwise direction is determined by the best cost in all directions; Figure 9 also shows the spore $p_{12}=1$ and the surrounding nodes, after the reply direction is obtained by calculating the costs of the links: 1-016, 1-3999, 1-616, 1-7999, $1-4999,1-7999,1-10,1-616$, values which are obtained using the cost matrix of Figure 4, finding that the first greater value different from 999 and 0 is node $p_{13}$, so the development of the spore is $p_{12} \rightarrow p_{13}$, and then spore $p_{13}$ is used and the process is repeated.

\begin{tabular}{|l|l|l|}
\hline 7 & 1 & 6 \\
\hline 4 & 1 & 0 \\
\hline 7 & 6 & 3 \\
\hline
\end{tabular}

Figure 9. Spore $p_{14}$ and its possible development directions.

Given element $p_{i j}$, which will start the development of the hypha, the jump is given by element $p m n$, where

$$
\begin{gathered}
(m, n) \in\{(i, j+1),(i+1, j+1)(i+1, j) \\
(\mathrm{i}+1, j-1)(i, j-1)(i-1, j-1) \\
(i-1, j)(i-1, j+1)\}
\end{gathered}
$$

The choice of the direction is given by the calculation of the costs of each pair in equation (4), and the first cost will indicate the direction. After repetitions with a spore, the hypha is constituted as shown in Figure 10, having row 0, row 7, column 1, and column 6 as limits.

Starting the spores in the lowest cost rows, positive properties are transmitted to the lower rows, improving their characteristics by combining them with elements of the rows with the lowest costs.

\section{Simulation Scenario}

In the literature we can find different topologies of optical networks which in general are those that 


\begin{tabular}{|c|c|c|c|c|c|c|c|c|c|c|c|c|c|c|c|c|c|c|c|}
\hline & 0 & 1 & 2 & 3 & 4 & 5 & 6 & 7 & Costos & & 0 & 1 & 2 & 3 & 4 & 5 & 6 & 7 & Costos \\
\hline 0 & 6 & 7 & 1 & 6 & 5 & 3 & 5 & 3 & 1095 & 0 & 6 & 7 & 1 & 6 & 5 & & 5 & 3 & 1095 \\
\hline 1 & 6 & 4 & 1 & 0 & 4 & 7 & 2 & 3 & 3061 & 1 & 6 & 4 & 1 & 1 & 4 & 7 & 1 & 3 & 3061 \\
\hline 2 & 6 & 7 & 6 & 3 & 0 & 2 & 3 & 3 & 2062 & 2 & 6 & 7 & 6 & 1 & 1 & 1 & 1 & 3 & 2062 \\
\hline 3 & 6 & 0 & 4 & 1 & 1 & 7 & 3 & 3 & 4995 & 3 & 6 & 0 & 4 & 1 & 1 & 7 & 3 & 3 & 4995 \\
\hline 4 & 6 & 0 & 5 & 1 & 2 & 3 & 4 & 3 & 5027 & 4 & 6 & 0 & 5 & 1 & 2 & 3 & 4 & 3 & 5027 \\
\hline 5 & 6 & 1 & 1 & 5 & 2 & 2 & 6 & 3 & 4012 & 5 & 6 & 1 & 1 & 5 & 2 & 2 & 6 & 3 & 4012 \\
\hline 6 & 6 & 7 & 1 & 6 & 6 & 6 & 2 & 3 & 2046 & 6 & 6 & 7 & 1 & 6 & 6 & 6 & 2 & 3 & 2046 \\
\hline & 6 & 2 & 5 & 1 & 4 & 6 & 0 & 3 & 6010 & 7 & 6 & 2 & 5 & 1 & 4 & 6 & 0 & 3 & 6010 \\
\hline
\end{tabular}

Figure 10. Generation of the hypha for a spore.

interconnect large cities at long distances, but in this study use is made of the NSFNET (Network Science Foundation NETwork) network implemented in the USA due to the need to compare results with previously published algorithms such as genetic and bacterial flagella algorithms. To make that comparison, use was made of the parameters applying the topology of 14 nodes, 21 links, and eight wavelengths (see Figure 11). On the other hand, the traffic request at all the nodes has a uniform distribution, the requests for service at each node have Poisson characteristics, without limits in the number of jumps, and without reattempts once the request has been blocked, and these conditions are similar to the simulation scenario of the two previously mentioned algorithms $[6,10,17]$.

The load was varied from 10 up to 180 erlangs, and it was calculated as the product of the mean rate of arriving requests and the mean holding time.

\section{RESULTS AND DISCUSSION}

Figure 12 shows the comparison of the distributions of Blocking Probability (BP) for the three algorithms

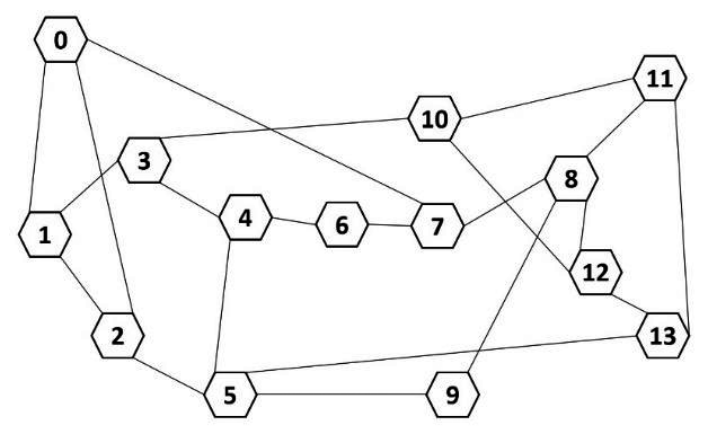

Figure 11. WDM-WCC optical network, NSFNET National Science Foundation NETwork. called bioalgorithms. It is seen that the FHA algorithm achieves better results in BP for loads greater than 130 erlangs, but below these loads it is better than the GEN algorithm, but not better than the FBA algorithms. The results RF shown in the next figures is a reference algorithm $[12,17]$.

Figure 13 shows the comparison of the Network Use (NU) distribution, where the FHA algorithm improves the FBA algorithm, but does not improve the genetic algorithm, and it is better than the RF reference algorithm. This indicates that the FHA algorithm succeeds in improving the blocking probability in high stress zones, but at a high cost in the use of the network's resources.

To achieve a better comparison, the mean values of the blocking probability of each heuristic along the 180 erlangs were calculated, showing in Figure 14 the low mean value of BP for the FHA algorithm, determining its low performance attending the future demand operating at high stress levels. This

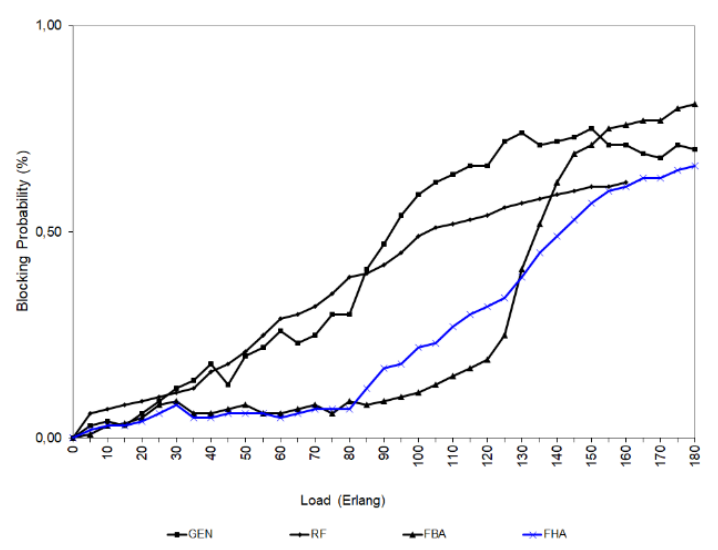

Figure 12. Distribution Blocking Probability. 
result places the FHA among the best algorithms, and certainly as the best among the bioalgorithms discussed in this article.

Evaluating the mean value of the network's use similarly to the previous conditions, Figure 15 shows a contrast with respect to the results of the blocking probability, that is, the cost of lowering the blocking probability is an increase of the use of the network's resources. This determines that the genetic algorithm makes better use of the resources, but it does not improve on the PBA and FHA in high stress scenarios.

To make a comparison of the bioalgorithms, an indicator called Algorithmic Capacity Index (ACI) was constructed, which is expressed as the ratio of the change of use of the network with respect to the blocking probability, as shown in equation (5). The results are shown in Figure 16, where a high ACI value indicates a high performance of the blocking probability (low) from using network resources. So, it is seen that the performance of FBA and FHA is

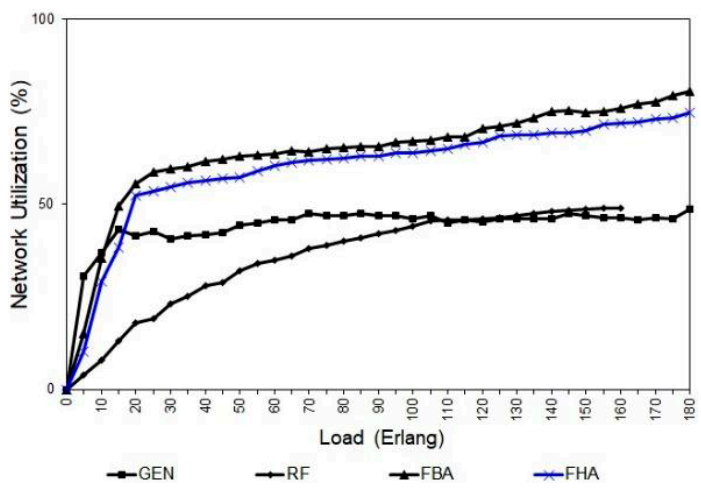

Figure 13. Distribution of the network utilization.

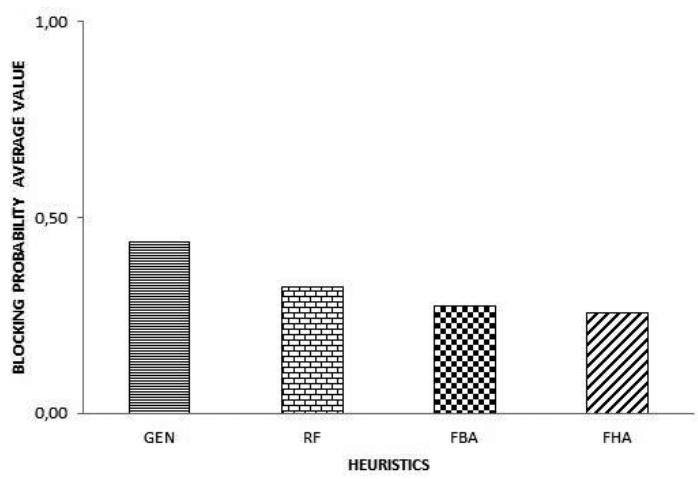

Figure 14. Mean value of the blocking probability. high for loads between 10 and 100 erlangs, indicating that for low stress the bioalgorithms perform better, and on the other hand, when the traffic scenario rises to stress levels, these algorithms operate similarly to the reference algorithm.

$$
A C I=\frac{U R}{P B} \forall U R \in[0,100] \Lambda P B \in[0,1]
$$

\section{CONCLUSIONS}

The comparison of the bioalgorithms with the FBA and FHA algorithms shows that the latter have a better overall performance, but there are specific scenarios where the results contrast, that is, the genetic algorithm is sensibly better in the bloccking probability for lower traffic loads, but at the expense of a high network use, and on the other hand, the FHA algorithm that was studied has

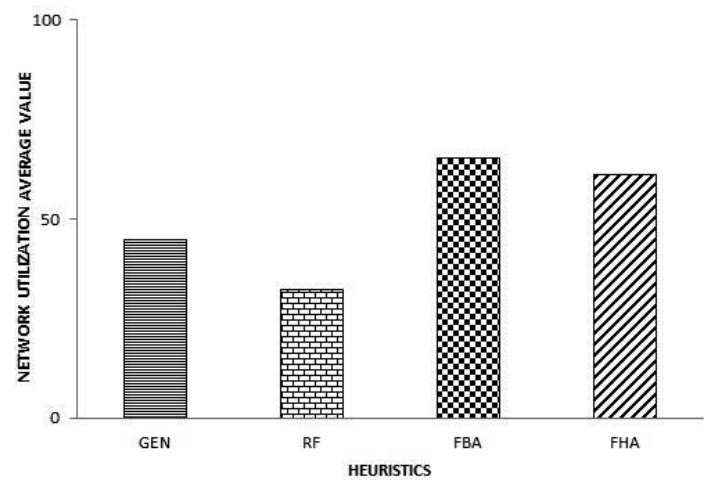

Figure 15. Mean value of the network's use.

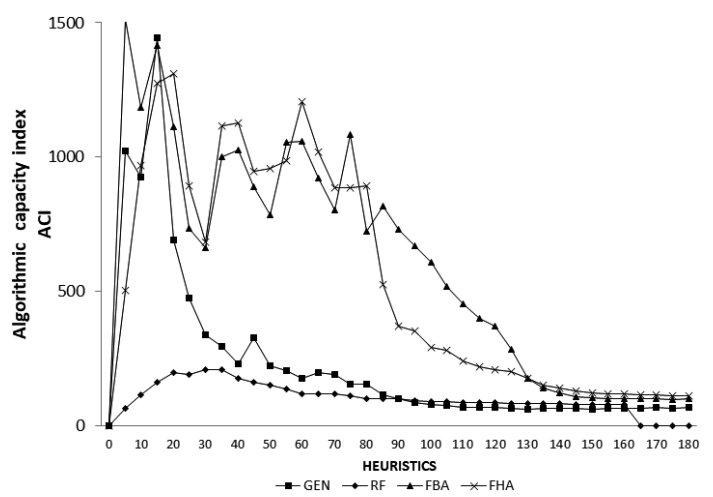

Figure 16. Distribution of the ACI for the studied bioalgorithms compared to the reference algorithm. 
a better comparative performance in the blocking probability, and from the overall standpoint with the ACI, implying that its use in the luminous routing for low stress scenarios is very important, but if the scenario is high stress, the bioalgorithms and even the reference ones perform similarly. In addition, when comparing the average values of blocking probability and network utilization, the GEN algorithm has a blocking probability close to 0.5 which contrasts with the FHA that is close to 0.3 , placing the FHA as one of the best algorithms for light routing, on the other hand, when comparing network utilization, it is observed that FHA and FBA consume more than $50 \%$ of network resources, in contrast to GEN that their consumption is less than $50 \%$. The study of these algorithms in scenarios of multifiber optical networks and with wavelength conversion is interesting. Finally, the comparative analysis shows that the proposed algorithm decreases the blockage probability and the use of the network, improving the performance of the bioalgorithms.

\section{ACKNOWLEDGMENTS}

Para el Proyecto Dicyt Código: 081871GM_DAS, Vicerrectoría de Investigación, Desarrollo e Innovación de la Universidad de Santiago de Chile - USACH, y al Grupo de Investigación en Nuevas Tecnologías (GINT-DTI-USACH) por el importante apoyo al desarrollo de la investigación.

\section{REFERENCES}

[1] K. Assis, D. Ferreira and W. Giozza. "Hybrid Algorithms for Routing and Assignment Wavelengths in Optical Networks". Latin America Transactions. Vol. $8 \mathrm{~N}^{\circ}$ 1, pp. 214220. 2010.

[2] J. Brandao, T. Noronha and C. Ribeiro. "A biased random-key genetic algorithm to maximize the number of accepted lightpaths in WDM optical networks". Journal of Global Optimization. Vol. $65 \mathrm{~N}^{\circ}$ 4, pp. 813-835. 2016.

[3] J. Brigitte and M. Daryalal. "Efficient Spectrum Utilization in Large Scale RWA Problems". IEEE-ACM Transactions on Networking. Vol. $25 \mathrm{~N}^{\circ}$ 2, pp. 1263-1278. 2017.

[4] C. Bonnie and M. Hughes. "The flagellum in bacterial pathogens: for motility and a whole lot more", PII: S1084-9521(15)00230-Xm.
2015. DOI: http://dx.doi.org/doi:10.1016/j. semcdb.2015.10.032

[5] O. Castrillón, W. Sarache y J. Giraldo. "Parámetros Numéricos en el Método de los Algoritmos Genéticos para el Sublimación". Inf. tecnol. Vol. $22 \mathrm{~N}^{\circ}$ 1, pp. 83-92. 2011.

[6] C. Duhamel, P. Mahey, A. Martins, R. Saldanha and M. de Souza. "Modelhierarchical column generation and heuristic for the routing and wavelength assignment problem". 4OR. Vol. $14 \mathrm{~N}^{\mathrm{o}}$ 2, pp. 201-220. 2016.

[7] A. Lehmann, W. Zheng, K. Soutschek, J. Roy, A.M. Yurkov and M.C. Rillig. "Tradeoffs in hyphal traits determine mycelium architecture in saprobic fungi". Sci Rep. 2019 Oct 2. Vol. $9 \mathrm{~N}^{\circ}$ 1, Art. 14152. DOI: 10.1038/ s41598-019-50565-7. PMID: 31578362; PMCID: PMC6775140.

[8] G. Li, D. Wang, J. Yates and R. Doverspike. "IP over Optical Cross-Connect Architectures". IEEE Communications Magazine. Vol. 45, pp. 34-39. 2007.

[9] N. Money. "Insights on the mechanics of hyphal growth. Fungal Biology Reviews". Vol. $22 \mathrm{~N}^{\mathrm{o}}$ 2, pp. 71-76. 2008.

[10] A. Rodriguez y F. Saavedra.”Optimización del Algoritmo Genético para la Solución Integral de Enrutamiento en Redes Fotónicas". Inf. tecnol. Vol. 21 N$^{\circ}$ 3, pp. 125-133. 2010.

[11] A. Rodriguez, R. Chávez and A. Ganga. "Routing Wavelength Assignment: Novel Heuristic Based on Bacterial Flagella for Optical Networks". Lecture notes in electrical, electronic and Computer Engineering. Vol. 1, pp. 29-37. 2019.

[12] A. Rodríguez, L. Ramirez and J. Martinez. "Heuristic algorithms: Novel solution for RWA problem in WDM optical networks". Journal of Telecommunication, Electronic and Computer Engineering. Vol. $10 \mathrm{~N}^{\mathrm{o}} 1-4$, pp. 1-7. 2018.

[13] J. Rosete y A. Vega. "Aplicación de Algoritmos Neurogenéticos en la Planeación de las Trayectorias de un Robot Polar". Inf. tecnol. Vol. 17 No 3, pp. 157-165. 2006.

[14] D. Turrà, D. Nordzieke, S. Vitale, M. El Ghalid and A. Di Pietro. "Hyphal chemotropism in fungal pathogenicity". Seminars in Cell \& Developmental Biology. Vol. 57, pp. 69-75. 2016. 
[15] D. Sharma and S. Kumar. "Network blocking probability-based evaluation of proposed spectrum assignment strategy for a designed elastic optical network link". Journal of Optics-India. Vol. $47 \mathrm{~N}^{\circ}$ 4, pp. 496-503. 2018.

[16] H. Zang and J. Jue. "Dynamic Lightpath Establishment in Wavelength-Routed WDM Networks", IEEE Communications Magazine. Vol. 39, pp. 100-108. 2001.
[17] H. Zang, J. Jue and B. Mukherjee. "A review of routing and wavelength assignment approaches for wavelength-routed optical WDM networks". Optical Network Magazine. Vol. 1, pp. 47-60. 2000.

[18] A. Zakouni, J. Luo and F. Kharroubi. "Genetic algorithm and tabu search algorithm for solving the static manycast RWA problem in optical networks". Journal of Combinatorial Optimization. Vol. $33 \mathrm{~N}^{\circ}$ 2, pp. 726-741.2017. 